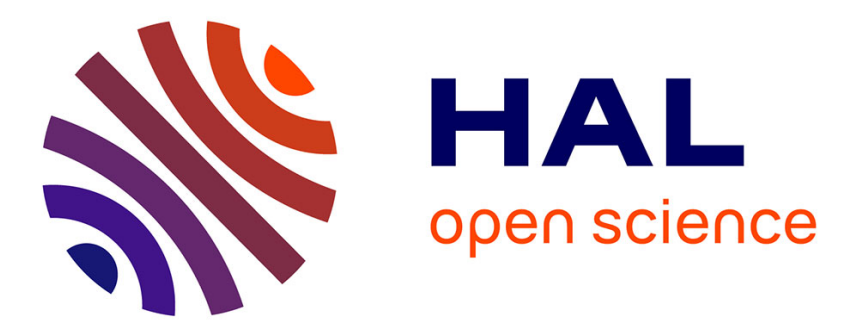

\title{
The population determines whether and how life-history traits vary between reproductive events in an insect with maternal care
}

\author{
Tom Ratz, Jos Kramer, Michel Veuille, Joël Meunier
}

\section{- To cite this version:}

Tom Ratz, Jos Kramer, Michel Veuille, Joël Meunier. The population determines whether and how life-history traits vary between reproductive events in an insect with maternal care. Oecologia, 2016, 182 (2), pp.443 - 452. 10.1007/s00442-016-3685-3 . hal-01740781

\author{
HAL Id: hal-01740781 \\ https://hal.science/hal-01740781
}

Submitted on 29 May 2020

HAL is a multi-disciplinary open access archive for the deposit and dissemination of scientific research documents, whether they are published or not. The documents may come from teaching and research institutions in France or abroad, or from public or private research centers.
L'archive ouverte pluridisciplinaire $\mathbf{H A L}$, est destinée au dépôt et à la diffusion de documents scientifiques de niveau recherche, publiés ou non, émanant des établissements d'enseignement et de recherche français ou étrangers, des laboratoires publics ou privés. 
1 The population determines whether and how life-history traits vary between

2 reproductive events in an insect with maternal care.

3 Tom Ratz ${ }^{1}$, Jos Kramer ${ }^{1}$, Michel Veuille ${ }^{2}$, Joël Meunier ${ }^{1,3 *}$

$4 \quad{ }^{1}$ Zoological Institute, Evolutionary Biology, Johannes Gutenberg University Mainz, Mainz,

5 Germany

62 Institut Systématique Evolution Biodiversité ISYEB - UMR 7205 CNRS, MNHN, UPMC,

7 EPHE, Paris-Sciences-Lettres, Paris 75005, France.

$8{ }^{3}$ Institut de Recherche sur la Biologie de l'Insecte, UMR 7261, CNRS, Université François-

9 Rabelais de Tours, Tours, France

$10 *$ Corresponding Author: Joel Meunier, joel.meunier@univ-tours.fr

11 Declaration of authorship: TR, JK, MV and JM designed the experiment. MV collected the

12 individuals in the field. TR and JK conducted the experiment. TR and JM analysed the data.

13 JM wrote the first draft of the manuscript, which was then commented and corrected by all 14 co-authors. 


\section{Abstract}

15 The last reproductive event of a female is often associated with major changes in terms of

16 both maternal and offspring life-history traits. However, the nature of these changes and

17 the importance of population-specific environmental constraints in shaping their

18 expression are difficult to predict and, as a consequence, poorly understood. Here, we

19 investigated whether and how life-history traits vary between reproductive events and

20 whether this variation is population-dependent in the European earwig Forficula

21 auricularia. In this insect species, females produce up to two clutches during their lifetime

22 and express extensive forms of maternal care. We conducted a common garden

23 experiment, in which we measured 11 life-history traits of the first and second clutches of

24132 females originating from three populations. Our results showed that clutch size was

25 higher - and the level of care expressed towards juveniles lower - in second as compared to

26 first clutches in all three populations. By contrast, we found a population-specific effect on

27 whether and how the reproductive event shaped juvenile quality and a trade-off between

28 egg developmental time and female weight at hatching. Overall, these findings emphasize

29 that the last reproductive event of a female entails both positive and negative effects on

30 various life-history traits of the female herself and her clutch of juveniles. Moreover, our

31 study stresses the importance of population idiosyncrasies on the expression and nature of

32 such cohort-specific effects.

34 Keywords: senescence, terminal investment, parental care, family life, semelparity, insect 


\section{Introduction}

Life-history traits are crucial phenotypic variants that reflect how an organism allocates time and energy to optimise its development and maximise its reproduction (Roff 1992; Stearns 1992; Flatt and Heyland 2011). These traits can be divided in a great diversity of categories, including the reproductive capability and success of an individual (e.g. age and size at maturity, number and size of offspring), as well as its physiology (e.g. immunocompetence and senescence) and behaviours (e.g. aggressiveness, reproductive tactics and parental care; Southwood 1977, Brommer 2000, Reznick et al. 2000). Studying the determinants of life-history traits is thus a pivot of evolutionary biology and ecology, as it helps to better understand the evolutionary constraints that shape the multiple aspects of an individual's fitness and, more generally, the factors that drive the evolution of populations and species (Stearns 1992; Schluter 2001; Rundle and Nosil 2005).

Numerous factors are known to either positively or negatively influence an individual's life-history traits (see examples in Stearns 1992; Nylina and Gotthard 1998; Flatt and Heyland 2011). The nature of the effects of being produced during the late reproductive period of a female (thereafter called 'cohort'), however, remains controversial. On the one hand, offspring can benefit from being produced in a late cohort. This is mostly because parental effort into reproduction is predicted to increase when the parents' prospects for survival and future reproduction decline (the 'terminal investment' hypothesis; (Williams 1966; Clutton-Brock 1984; Javoiš 2013)) and this might benefit offspring if the increase is allocated to parental care (rather than to the production of additional offspring). Over the last decades, numerous studies conducted across species and taxa provided empirical support for this prediction (Fox and Czesak 2000; Hasselquist and Nilsson 2009; Royle et al. 2012; Santos and Nakagawa 2012). For instance, females of the North American red 
squirrels Tamiasciurus hudsonicus and the burying beetle Nicrophorus orbicollis have been shown to produce juveniles of better quality (and/or more juveniles) in late compared to early cohorts (Descamps et al. 2007; Creighton et al. 2009). Similarly, parents showed higher levels of parental care for late- as compared to early-produced juveniles in the collared flycatcher Ficedula albicollis and in N. orbicollis (Part et al. 1992; Creighton et al. 2009).

On the other hand, offspring may also suffer from being produced in a late cohort.

This cost often results from physiological constraints that hamper the expression of parental investment and thus ultimately decrease offspring quality (reviewed in Javoiš 2013). Maternal senescence is a well-known physiological constraint that negatively and specifically affects juveniles of late cohorts, as aging females usually become unable to increase or even maintain their reproductive efforts (McNamara and Houston 1996; Nussey et al. 2013; Kowald and Kirkwood 2015). For instance, in the grey seal Halichoerus grypus, maternal and offspring body mass, weaning mass and the level of lactation have all been shown to decline with age due to physiological degeneration (Bowen et al. 2006). Importantly, (often population-specific) environmental constraints such as food restriction and pathogen presence can either promote or hamper the expression of a terminal investment and may thus have a substantial influence on the traits of late cohort offspring. For instance, low food intake has been shown to inhibit the expression of terminal investment by females of the Alpine chamois Rupicapra rupicapra (Mason et al. 2011), whereas food restriction and pathogen presence favoured its expression in males of the yellow mealworm beetle Tenebrio molitor (Krams et al. 2015) and of the blue-footed booby Sula nebouxii (Velando et al. 2006), respectively. Although environmental constraints often vary between populations, the occurrence of population-specific differences in the lifehistory traits expressed by individuals from early and late cohorts remains surprisingly 
poorly studied (see Mason et al. 2011; Javoiš 2013; Vincze et al. 2013).

In this study, we investigated whether maternal and offspring life-history traits vary between initial and terminal reproductive events in the European earwig Forficula auricularia, and whether the occurrence and nature of this variation are populationspecific. In this insect species, females produce up to two clutches during their one-year lifespan: the initial clutch of eggs is generally produced in early-winter and hatches in the following early-spring, while the terminal clutch (when present) is produced in mid-spring and hatches in the following early-summer (Meunier et al. 2012). From the date of egg laying until several weeks after egg hatching, mothers provide extensive forms of care to their eggs and juveniles (called nymphs) that include the protection against predators and pathogens, as well as the provisioning of nymphs with food (e.g. through regurgitation; Lamb 1976; Kölliker 2007; Boos et al. 2014; Koch and Meunier 2014; Diehl et al. 2015; Kölliker et al. 2015).

In a previous study focusing on differences between semelparous and iteroparous F. auricularia females, Meunier et al. (2012) showed that the $2^{\text {nd }}$ clutches of iteroparous females were smaller and developed faster than their $1^{\text {st }}$ clutches. However, it remains unknown whether this variation (1) shapes other key life-history traits of earwigs, such as maternal condition and the expression of maternal care and, more importantly, whether it (2) depends on the studied population. Here, we addressed these questions by comparing a total of eleven life-history traits measured in the $1^{\text {st }}$ and $2^{\text {nd }}$ clutches of $132 \mathrm{~F}$. auricularia females sampled in three distant populations in Europe. These traits encompassed measures of clutch quantity and quality, maternal condition during post-hatching family interactions, as well as the expression of brood defence and food provisioning, two important forms of post-hatching maternal care (Meunier and Kölliker 2012; Thesing et al. 


\section{Materials and methods}

107

108

109

110

111

112

113

114

115

\section{Field sampling and laboratory breeding}

Our experiment started with 696 F. auricularia individuals sampled in September 2014 in three populations located in Girona (Spain, $\mathrm{n}=120$ females and 118 males), Montblanc (Spain, $\mathrm{n}=118$ females and 107 males) and Vincennes (France, $\mathrm{n}=119$ females and 114 males) (Figure 1). All these populations belong to the same $F$. auricularia genetic clade $B$ (Wirth et al. 1998)(M. Veuille and X. Espalader, unpublished data), and are subjected to different environmental conditions in terms of altitude, temperature and precipitation (see details in Figure 1). Note that neither of these populations corresponded to the population studied in Meunier et al. (2012).

Individuals from all three populations were maintained under standard laboratory conditions adapted from Meunier et al (2012). This allowed the expression of inherited population-specific traits while controlling for plastic responses to the environment. The setup started by haphazardly distributing all field-sampled individuals of each population among large plastic containers to form groups of $58 \pm 0.58$ (mean \pm SE) individuals encompassing a maximum of 30 males and 30 females. These groups were maintained at $20^{\circ} \mathrm{C}, 60 \%$ humidity, $14: 10 \mathrm{~h}$ light: dark photoperiod (thereafter called summer conditions) to allow uncontrolled mating (Sandrin et al. 2015). Two months later, a random sample of 237 females (Girona: $n=71$; Montblanc: $n=59$; Vincennes: $n=107$ ) was isolated to allow egg production. These females were maintained under complete darkness and $60 \%$ humidity, with a temperature of $10^{\circ} \mathrm{C}$ for 2 weeks, and then $5^{\circ} \mathrm{C}$ for three months to mimic 
winter conditions. Spring was subsequently simulated by first increasing the temperature to $10^{\circ} \mathrm{C}$ and one week later to $15^{\circ} \mathrm{C}$. When the first nymph hatched, the corresponding family was transferred to and maintained under summer conditions (see above) to favour nymph development. Fourteen days later, each female was isolated to mimic natural family

131 disruption and subsequently maintained under complete darkness to allow $2^{\text {nd }}$ clutch 132 production (Meunier et al. 2012). The laboratory rearing of $2^{\text {nd }}$ clutch eggs and nymphs was similar to the above detailed rearing of the $1^{\text {st }}$ clutches, except that eggs were maintained under summer temperatures. Among the 209 females that produced $1^{\text {st }}$ clutch nymphs (28 were discarded from the experiment.

\section{Measurements of 11 life-history traits}

149 We investigated the effects of population and juvenile cohort on a total of 11 life-history 
traits reflecting clutch quantity and quality, maternal condition during post-hatching family

151 interactions, and post-hatching maternal care. These measurements started with the (1)

152 egg developmental time, which was defined as the number of days between the first day of

153 egg laying and the first day of egg hatching. We then counted (2) the number of eggs

154 produced within three days after the first egg laying, (3) the number of nymphs present one 155 day after the first egg hatching and (4) the number of nymphs alive 14 days after hatching.

156 We used different timespans for the first two countings, because $F$. auricularia females 157 generally need up to three days to finish the deposition of their clutch of eggs, whereas egg 158 hatching is well synchronised within each clutch and is generally completed over a single 159 day (Koch and Meunier 2014). We also measured the (5) mean weight of nymphs one day 160 and (6) 14 days after egg hatching. To this end, a group of 10 nymphs (or all nymphs if brood 161 size was lower than 10) was haphazardly sampled in each brood and weighed to the nearest 1620.01 mg using a microscale (model MYA5; PESCALE, Bisingen, Germany). We then recorded 163 (7) the developmental time of nymphs from the first to the second developmental instar, 164 which was obtained by counting the number of days between egg laying and the emergence 165 of the first second instar nymph in each clutch. This measurement is known to reflect the 166 developmental time of the entire clutch in F. auricularia (Gómez and Kölliker 2013). Finally, 167 changes in maternal condition over the period of post-hatching family interactions were 168 measured by weighing each mother (8) one day and (9) 14 days after the first egg hatching. Post-hatching maternal care was estimated by measuring food provisioning and 170 brood defence. (10) Food provisioning was measured in 102 clutches (a haphazard sample 171 of 34 clutches was omitted from this measurements due to time constraints; see details in 172 table 1) using a standard method relying on the fact that ingested coloured food is visible 173 through the partially transparent cuticle of $1^{\text {st }}$ instar nymphs (Staerkle and Kölliker 2008; 
174 Kölliker et al. 2015; Kramer et al. 2015). In brief, food was removed from each family on day

1755 after hatching. Twenty-four hours later, mothers were isolated and had access to a green

176 pollen pellet (naturally yellow-coloured pollen coloured with blue dye; Hochland Bio-

177 Blütenpollen by Hoyer; Food die by DEKO BACK) for one hour. Afterwards, mothers were

178 returned to a standardised number of 20 of their own nymphs (or all of their nymphs if the

179 clutch had less than 20 nymphs; mean number of nymphs used in this test \pm SE $=18.9 \pm$

$1800.21)$ to allow family interactions. Finally, the number of green-coloured and non-green-

181 coloured nymphs was counted fifteen hours later using a stereomicroscope (Leica S8 APO,

182 10x). Note that food provisioning was not measured in clutches with less than five nymphs

$183(n=5)$ and that the level of food provisioning was independent of the number of recipient

184 nymphs (Spearman correlation test, $r h o=-0.08, S=23869, p=0.577$ ). During the food

185 provisioning test, all left-over nymphs were maintained in their original Petri dish and

186 provided with standard laboratory food. To follow the treatments detailed above, all

187 unused families were starved for $24 \mathrm{~h}$ on day 5 and fed again on day 6 .

188 Finally, (11) brood defence was assessed using a previously established method

189 (Thesing et al. 2015), in which each female was standardly poked on the pronotum with a

190 glass-capillary (one poke per second) to record the number of pokes necessary to induce

191 her running away beyond a distance of twice the female's body length. Brood defence was

192 tested at day 4, day 8, and day 12 after hatching and the average of these three values was

193 used as brood defence. The brood defence test was carried out under red light, as earwigs

194 are nocturnal.

195 Statistical analyses

196 We were first interested in testing the effects of population and the juveniles' cohort on the 
197 life-history traits of mothers and offspring. To control for possible non-independence 198 among the 11 measured traits, we first conducted a Principal Component Analysis (PCA) to 199 obtain non-correlated principal components (PCs) reflecting single or combinations of 200 different life-history traits. In this PCA, the values of food provisioning were logit201 transformed and the values of brood defence were log-transformed to comply with normal 202 distributions. The PCA was conducted by scaling the data to unit variance and running a 203 regularised iterative MFA method (with K-fold cross-validation) to handle the few missing 204 values in the dataset (Lê et al. 2008, Husson et al. 2011). The resulting and selected PCs 205 (Table 2) were then analysed separately using Linear Mixed Models (LMMs), in which the 206 population, the juveniles' cohort and their interaction were entered as fixed factors and 207 female ID was used as a random factor (Table 3). In case of significant interactions between 208 population and the juveniles' cohort (see results), pairwise comparisons among each 209 combination were tested using Tukey HSD tests.

210 To determine the occurrence of an investment trade-off between $1^{\text {st }}$ and $2^{\text {nd }}$ 211 clutches, we also tested whether the life-history traits measured in $2^{\text {nd }}$ and $1^{\text {st }}$ clutches were 212 negatively (i.e. reproductive trade-off) or positively (i.e. quality-dependent reproduction) 213 correlated, and whether the occurrence and nature of these correlations were similar 214 across populations. To this end, we conducted a series of five General Linear models (LM), 215 in which the $2^{\text {nd }}$ clutch values of each of the five above PCs were used as a response variable, 216 while the corresponding $1^{\text {st }}$ clutch values, the population and their interaction were entered 217 as fixed variables. All statistical analyses were conducted using R v 3.2.1 (http://www.r218 project.org/) loaded with the packages car, FactoMineR, missMDA, ImerTest and Ismeans. 


\section{Results}

219 Overall, 52 (83.8\%) of the 62 females from Girona, 39 (72.2\%) of the 54 females from

220 Montblanc and 45 (48.4\%) of the 93 females from Vincennes produced two clutches of

221 nymphs (Pearson's Chi-squared test, $\chi^{2}{ }_{2}=22.25, p<0.0001$ ). These proportions were

222 significantly smaller in Vincennes compared to both Girona $\left(\chi^{2}{ }_{1}=20.00, p\right.$-value $\left.<0.0001\right)$

223 and Montblanc $\left(\chi^{2}{ }_{1}=7.93, p\right.$-value $\left.=0.005\right)$, but comparable between the two Spanish

224 populations $\left(\chi^{2}{ }^{2}=2.32, p=0.128\right)$.

The PCA conducted on the life-history traits measured in the $1^{\text {st }}$ and $2^{\text {nd }}$ clutches of

226 these 136 females provided 11 orthogonal principal components (PCs), of which we

227 extracted the first five ones (total variance explained $=87.2 \%$, Table 2 ). The first component

228 (PC1) was highly and positively loaded with the number of eggs as well as with the number

229 of nymphs at day 1 and day 14 , therefore overall positively reflecting clutch size. The second

230 component (PC2) revealed a positive association between the nymphs' weights on day 1

231 and day 14, as well as post-hatching developmental speed, which overall reflects nymph

232 quality. Accordingly, high values of PC2 indicate that clutches consisted of heavy nymphs

233 which quickly moulted into the second developmental instar, whereas small values indicate

234 clutches with light nymphs which required more time to develop into the second instar. The

235 third component (PC3) revealed a trade-off between egg developmental time and the

236 mother's weight at egg hatching. High values of PC3 thus represent clutches in which eggs

237 required a long time to develop and mothers were light at egg hatching (probably because

238 they spent more time caring for the eggs), whereas small values reflect clutches in which

239 eggs developed fast and mothers were heavy at egg hatching. Finally, the fourth (PC4) and

240 fifth (PC5) components were solely and positively loaded with brood defence and food 
provisioning, respectively.

An interaction between population and the juvenile's cohort significantly shaped

243 PC1, PC2 and PC3 (Table 3). For PC1, pairwise comparisons within the statistical model

244 showed that $1^{\text {st }}$ clutches were overall larger than $2^{\text {nd }}$ clutches within each population,

245 whereas the interaction emphasized that this difference was smaller in Vincennes as

246 compared to Girona and Montblanc (Figure 2a, Table S1). By contrast, the interactive effect

247 of population and the juveniles' cohort on PC2 revealed that $1^{\text {st }}$ clutch nymphs were of

248 lower quality than $2^{\text {nd }}$ clutch nymphs in Vincennes, but not in Girona and Montblanc (Figure

249 2b). Similarly, the significant interaction shaping PC3 showed a slower developmental time

250 of eggs and a lighter weight of females at hatching in the $1^{\text {st }}$ compared to the $2^{\text {nd }}$ clutches

251 in Girona and Montblanc, but not in Vincennes (Figure 2c). Note that the raw values of each

252 trait can be found in Table 1.

The values of PC4 and PC5, which respectively reflected the level of brood defence

254 and food provisioning, were overall higher in the $2^{\text {nd }}$ compared to $1^{\text {st }}$ clutches (Table 3 and

255 Figure 3). However, they were independent of the population or of an interaction between

256 population and the juvenile's cohort (Table 3).

Finally, we found consistencies (i.e. positive associations) across the two breeding attempts (Table 4) in terms of clutch size (PC1; Model estimate $\pm \mathrm{SE}=0.697 \pm 0.039, \mathrm{t}=$

$25917.55, \mathrm{P}<0.0001)$, nymph quality (PC2; estim. $=0.375 \pm 0.091, \mathrm{t}=4.13, \mathrm{P}<0.0001)$, the

260 trade-off between egg developmental time and maternal weight at egg hatching (PC3;

261 estim. $=0.335 \pm 0.074, t=4.55, P<0.0001)$ and brood defence (PC4; estim. $=0.469 \pm 0.092$,

$262 t=5.10, P<0.0001)$, but not in terms of food provisioning ( $P C 5$; estim. $=0.086 \pm 0.083, t=$

263 1.04, $P=0.301$; Figure 3). The occurrence and strength of these associations were 264 independent of the population (interaction in Table 4). These statistical models also 
confirmed the results of the above analyses by showing that both clutch size and the trade-

266 off between egg developmental time and the mother's weight at egg hatching observed in 267 the $2^{\text {nd }}$ clutches were population specific (Table 4, Figure 2).

\section{Discussion}

268 This study overall shows that initial and terminal clutches of the European earwig $F$.

269 auricularia exhibit differences in life-history traits, and that the occurrence and nature of

270 these differences depend on the trait and/or the studied population. Specifically, we found

271 that nymph quality was higher in the $2^{\text {nd }}$ compared to $1^{\text {st }}$ clutches of Vincennes females

272 only, and that egg developmental time and female weight at hatching were longer and

273 lighter, respectively, in initial compared to terminal clutches of females from Girona and

274 Montblanc. By contrast, clutch size was lower and maternal care - i.e. brood defence and

275 food provisioning - higher in $1^{\text {st }}$ as compared to $2^{\text {nd }}$ clutches in all three studied populations.

276 Interestingly, the expression of all traits measured in the $1^{\text {st }}$ clutches (but food provisioning)

277 was positively associated with the expression of these traits in the $2^{\text {nd }}$ clutches, and the 278 occurrence and nature of these associations were independent of the studied population.

279 Across species and taxa, the expression of life-history traits often varies among 280 populations. This is the case, for instance, for offspring mass and number in the scorpion

281 Centruroides vittatus (Brown and Formanowicz 1995), for the juveniles' development and 282 survival in the Mediterranean fruit fly Ceratitis capitat (Diamantidis et al. 2011), and for the 283 level of parental care in the Kentish plover Charadrius alexandrinus and the snowy plover 284 C. nivosus (Vincze et al. 2013). In earwigs, our results do not only demonstrate that each 285 population is characterized by a specific proportion of females producing two clutches 
under identical (laboratory) conditions (see also Wirth et al. 1998; Meunier et al. 2012), but also that the population determines whether and how certain life-history traits differ between initial and terminal clutches.

Although females from the three populations were maintained under the same laboratory conditions, we found that their population of origin determined the effects of 291 the juveniles' cohort on nymph quality and the trade-off between egg developmental time 292 and female weight at hatching. This is important, as it reveals that these effects are not 293 determined by the environmental conditions experienced during family life, but instead 294 depend on the conditions experienced during female development and/or on (the 295 conditions that have shaped) the evolutionary history of the population. In line with the 296 first hypothesis, the quality of the environment experienced by $F$. auricularia juveniles 297 during their development is known to affect the life-history traits of the resulting adults, for 298 instance in terms of investment into $2^{\text {nd }}$ clutch production and maternal care (Wong and 299 Kölliker 2014; Thesing et al. 2015). Conversely, harsh winter conditions have been 300 suggested to select for a delayed production of $1^{\text {st }}$ clutch eggs (Meunier et al. 2012), which 301 may benefit females by shortening the developmental time of their $1^{\text {st }}$ clutch eggs and thus 302 allowing the mothers to exhibit a higher condition (i.e. a higher body weight) at hatching. 303 Ultimately, such conditions may prevent differences in the trade-off between egg 304 developmental time/female weight at hatching between $1^{\text {st }}$ and $2^{\text {nd }}$ clutches (which are 305 always produced in spring, under favourable environmental conditions), and might thus 306 explain its absence in females from Vincennes, the population with the coldest winter 307 (Figure 1) and the latest production of $1^{\text {st }}$ clutch eggs (Table 1). Whether our results are the 308 outcome of the interactive or independent effects of these two processes remains to be 309 further studied. 
311 females expressed higher levels of post-hatching care towards $2^{\text {nd }}$ compared to $1^{\text {st }}$ clutches

312 in all three tested populations. Notably, this effect was present even if the females' weight

313 at the beginning of family life (i.e. at egg hatching) was comparable between the two

314 clutches (see Table 1). These results are overall in line with a terminal investment of $F$.

315 auricularia females in terms of maternal care (Williams 1966; Clutton-Brock 1984; Javoiš

316 2013), as found in the collared flycatcher F. albicollis (Part et al. 1992) and the burying beetle

317 N. orbicollis (Creighton et al. 2009). Furthermore, these findings could indicate that the

318 benefits of maternal care are more important for $2^{\text {nd }}$ than $1^{\text {st }}$ clutch nymphs and therefore

319 select for higher expression of care towards late clutch nymphs across populations. In line

320 with this idea, spring is often well advanced when $2^{\text {nd }}$ clutch eggs hatch, so that the

321 environmental conditions experienced by the resulting nymphs are likely to increase (as

322 compared to $1^{\text {st }}$ clutch nymphs) their exposure to pathogens, such as fungi, or their

323 predators, such as other arthropods and even the $1^{\text {st }}$ clutch nymphs (Dobler and Kölliker

324 2010). Irrespective of the mechanism mediating the increased level of maternal care

325 towards $2^{\text {nd }}$ clutch nymphs, the absence of a population-specific effect indicates that the

326 environmental conditions experienced by females during $1^{\text {st }}$ clutch family life (and egg care)

327 are crucial in determining the subsequent expression of maternal care towards their $2^{\text {nd }}$

328 clutch offspring. This is supported by recent studies showing that maternal condition at egg

329 hatching determines the nature of sibling and mother-offspring interactions in F. auricularia

330 (Wong and Kölliker 2012; Kramer et al. 2015; Kramer and Meunier 2016).

331 Interestingly, we found a reduction in size of the $2^{\text {nd }}$ as compared to the $1^{\text {st }}$ clutch in

332 all three studied populations. This reduction is in line with an effect of senescence on female

333 reproduction, but may also reflect an adaptive strategy of females. For example, the 
334 uncertainty of surviving until $2^{\text {nd }}$ clutch production could favour a higher investment into $1^{\text {st }}$

335 clutch production independent of female age. Such an effect of the perceived risk of death

336 on female investment into reproduction has been nicely demonstrated in the burying beetle

337 Nicrophorus vespilloides, in which an experimental activation of the immune system caused

338 females to switch from reproductive restraint to terminal investment (Cotter et al. 2011).

339 Interestingly, our findings in earwigs reveal that although clutch sizes were different, almost

340 all measurements of life-history traits taken in the $1^{\text {st }}$ clutches were positively correlated

341 with the corresponding measurements in the $2^{\text {nd }}$ clutches. This highlights that the overall

342 reproduction of a female is tightly linked to her own quality irrespective of whether or not

343 senescence shapes the size of $2^{\text {nd }}$ clutches (Meunier et al. 2012). Further studies should be

344 conducted to experimentally disentangle the (mutually non-exclusive) effects on maternal

345 investment into egg production caused by senescence and/or the perceived risk of death

346 on the one hand, and the effects on maternal care caused by terminal investment and/or

347 reproductive strategy (see above).

To conclude, our study demonstrates that offspring cohort and population-

349 membership interact in determining crucial life-history traits in the European earwig. We

350 showed in a common garden experiment that population-membership affected the

351 expression of two cohort-specific traits only (nymph quality and the trade-off between egg

352 developmental time and female weight at egg hatching), suggesting an important role of

353 past environmental conditions in their expression, but also indicating a limited role of such

354 past conditions for the expression of maternal care. Although our results are overall in line

355 with an effect of terminal investment on maternal care, and of senescence on maternal

356 reproduction, our findings call for further experimental studies deciphering the

357 independent or entangled action of these mechanisms (see e.g. Cotter et al. 2011). Finally, 
358 it is important to note that the direction and strength of the cohort-specific effects reported

359 in this study should be interpreted with caution, as our laboratory conditions might have

360 unwillingly favoured individuals from certain populations. Nevertheless, our results

361 demonstrate that even within a single genetic clade (namely the F. auricularia clade B; Wirth

362 et al. 1998), population idiosyncrasies may have major effects on the expression of life-

363 history traits associated with successive reproductive attempts. The question whether

364 these idiosyncrasies reflect the capability of individuals to develop under specific laboratory

365 conditions, the evolutionary history of the population, and/or the biotic/abiotic constraints

366 experienced by the juveniles during their development remains open for further studies.

\section{Aknowledgments}

367 We thank all members of the "Team Earwig" at the university of Mainz for their help in the

368 maintenance of animals in the laboratory. We also thank Arnaud Suwalski from the EPHE

369 for species determination, Xavier Espalader for his help with earwig sampling, Jessica Purcell

370 for her help in obtaining climatic data for the three tested populations and two anonymous

371 reviewers for their comments on a previous version of this manuscript. This research was

372 supported by the German Science Foundation (DFG; ME4179/1-1 to JM) and the ARP-EVOL

373 grant from EPHE obtained by Claudie Doums. 


\section{References}

Boos S, Meunier J, Pichon S, Kölliker M (2014) Maternal care provides antifungal protection to eggs in the European earwig. Behav Ecol 25:754-761. doi: 10.1093/beheco/aru046

Bowen WD, Iverson SJ, McMillan JI, Boness DJ (2006) Reproductive performance in grey seals: age-related improvement and senescence in a capital breeder. J Anim Ecol 75:1340-51. doi: 10.1111/j.1365-2656.2006.01157.x

Brommer JE (2000) The evolution of fitness in life-history theory. Biol Rev 75:377-404. doi: 10.1111/j.1469-185X.2000.tb00049.x

Brown CA, Formanowicz DR (1995) Variation in reproductive investment among and within populations of the scorpion Centruroides vittatus. Oecologia 103:140-147. doi: 10.1007/BF00329073

Clutton-Brock TH (1984) Reproductive effort and terminal investment in iteroparous animals. Am Nat 123:212-229.

Cotter SC, Ward RJS, Kilner RM (2011) Age-specific reproductive investment in female burying beetles: independent effects of state and risk of death. Funct Ecol 25:652660. doi: 10.1111/j.1365-2435.2010.01819.x

Creighton JC, Heflin ND, Belk MC (2009) Cost of reproduction, resource quality, and terminal investment in a burying beetle. Am Nat 174:673-684. doi: 10.1086/605963

Descamps S, Boutin S, Berteaux D, Gaillard J-M (2007) Female red squirrels fit Williams' hypothesis of increasing reproductive effort with increasing age. J Anim Ecol 76:1192-1201. doi: 10.1111/j.1365-2656.2007.01301.x

Diamantidis AD, Carey JR, Nakas CT, Papadopoulos NT (2011) Population-specific demography and invasion potential in medfly. Ecol Evol 1:479-488. doi: 10.1002/ece3.33

Diehl JM, Körner M, Pietsch M, Meunier J (2015) Feces production as a form of social immunity in an insect with facultative maternal care. BMC Evol Biol 15:15:40. doi: 10.1186/s12862-015-0330-4

Dobler R, Kölliker M (2010) Kin-selected siblicide and cannibalism in the European earwig. Behav Ecol 21:257-263. doi: 10.1093/beheco/arp184

Flatt T, Heyland A (2011) Mechanisms of life history evolution: the genetics and physiology of life history traits and trade-offs. Oxford University Press, Oxford

Fox CW, Czesak ME (2000) Evolutionary ecology of progeny size in arthropods. Annu Rev Entomol 45:341-369.

Gómez Y, Kölliker M (2013) Maternal care, mother-offspring aggregation and agedependent coadaptation in the European earwig. J Evol Biol 26:1903-11. doi: 10.1111/jeb.12184

Hasselquist D, Nilsson J -a. (2009) Maternal transfer of antibodies in vertebrates: trans- 

364:51-60. doi: 10.1098/rstb.2008.0137

Husson F, Le S, Pagès J (2011) Exploratory multivariate analysis by example using R. Chapman and Hall / CRC press, London

Javoiš J (2013) A two-resource model of terminal investment. Theory Biosci 132:123-132. doi: 10.1007/s12064-013-0176-5

Koch LK, Meunier J (2014) Mother and offspring fitness in an insect with maternal care: phenotypic trade-offs between egg number, egg mass and egg care. BMC Evol Biol 14:125. doi: 10.1186/1471-2148-14-125

Kölliker M (2007) Benefits and costs of earwig (Forficula auricularia) family life. Behav Ecol Sociobiol 61:1489-1497. doi: 10.1007/s00265-007-0381-7

Kölliker M, Boos S, Wong JWY, et al (2015) Parent-offspring conflict and the genetic trade-

Kowald A, Kirkwood TBL (2015) Evolutionary significance of ageing in the wild. Exp

Kramer J, Meunier J (2016) Maternal condition determines offspring behavior toward family members in the European earwig. Behav Ecol 27:494-500. doi: 10.1093/beheco/arv181

Kramer J, Thesing J, Meunier J (2015) Negative association between parental care and sibling cooperation in earwigs: a new perspective on the early evolution of family life? J Evol Biol 28:1299-1308. doi: 10.1111/jeb.12655

Krams IA, Krama T, Moore FR, et al (2015) Resource availability as a proxy for terminal investment in a beetle. Oecologia 178:339-345. doi: 10.1007/s00442-014-3210-5

Lamb RJ (1976) Parental behavior in the dermaptera with special reference to Forficula auricularia (Dermaptera: Forficulidae). Can J Entomol 108:609-619.

Lê S, Josse J, Husson F (2008) FactoMineR : An R package for multivariate analysis. J Stat Softw 25:1-18. doi: 10.1016/j.envint.2008.06.007

Mason THE, Chirichella R, Richards S a., et al (2011) Contrasting life histories in neighbouring populations of a large mammal. PLoS One 6:e28002. doi: 10.1371/journal.pone.0028002

McNamara JM, Houston Al (1996) State-dependent life histories. Nature 380:215-221.

Meunier J, Kölliker M (2012) Parental antagonism and parent-offspring co-adaptation interact to shape family life. Proc R Soc B Biol Sci 279:3981-8. doi: $10.1098 / \mathrm{rspb} .2012 .1416$

Meunier J, Wong JWY, Gómez Y, et al (2012) One clutch or two clutches? Fitness correlates of coexisting alternative female life-histories in the European earwig. Evol Ecol 26:669-682. doi: 10.1007/s10682-011-9510-x

Nussey DH, Froy H, Lemaitre J-F, et al (2013) Senescence in natural populations of animals: Widespread evidence and its implications for bio-gerontology. Ageing Res Rev 
452

Nylin S, Gotthard K (1998) Plasticity in life-history traits. Annu Rev Entomol 43:63-83. doi: 10.1146/annurev.ento.43.1.63

Part T, Gustafsson L, Moreno J (1992) Terminal investment and a sexual conflict in the collared flycatcher (Ficedula albicollis). Am Nat 140:868-882.

Reznick D, Nunney L, Tessier A (2000) Big houses, big cars, superfleas and the costs of reproduction. Trends Ecol Evol 15:421-425. doi: 10.1016/S0169-5347(00)01941-8

Roff DA (1992) The evolution of life histories: Theory and analysis. Chapman and Hall, New York

Royle NJ, Smiseth PT, Kölliker M (2012) The evolution of parental care, Oxford Uni. Oxford University Press, Oxford

Rundle HD, Nosil P (2005) Ecological speciation. Ecol Lett 8:336-352. doi: 10.1111/j.14610248.2004.00715.x

Sandrin L, Meunier J, Raveh S, et al (2015) Multiple paternity and mating group size in the European earwig, Forficula auricularia. Ecol Entomol 40:159-166. doi: 10.1111/een.12171

Santos ES a, Nakagawa S (2012) The costs of parental care: a meta-analysis of the trade-off between parental effort and survival in birds. J Evol Biol 25:1911-7. doi: 10.1111/j.1420-9101.2012.02569.x

Schluter D (2001) Ecology and the origin of species. Trends Ecol Evol 16:372-380. doi: 10.1016/S0169-5347(01)02198-X

Southwood TRE (1977) Habitat, the templet for ecological strategies? J Anim Ecol 46:337365. doi: $10.2307 / 3817$

Staerkle M, Kölliker M (2008) Maternal food regurgitation to nymphs in earwigs (Forficula auricularia). Ethology 114:844-850. doi: 10.1111/j.1439-0310.2008.01526.x

Stearns SC (1992) The evolution of life histories. Oxford University Press, Oxford

Thesing J, Kramer J, Koch LK, Meunier J (2015) Short-term benefits, but transgenerational costs of maternal loss in an insect with facultative maternal care. Proc R Soc B Biol Sci 282:20151617. doi: 10.1098/rspb.2015.1617

Velando A, Drummond H, Torres $\mathrm{R}$ (2006) Senescent birds redouble reproductive effort when ill: confirmation of the terminal investment hypothesis. Proc R Soc B Biol Sci 273:1443-1448. doi: $10.1098 /$ rspb.2006.3480

Vincze O, Székely T, Küpper C, et al (2013) Local environment but not genetic differentiation influences biparental care in ten plover populations. PLoS One 8:e60998. doi: 10.1371/journal.pone.0060998

Williams GC (1966) Natural selection, the costs of reproduction, and the refinement of Lack's principle. Am Nat 100:687-690.

Wirth T, Guellec R Le, Vancassel M, Veuille M (1998) Molecular and reproductive 
characterization of sibling species in the european earwig (Forficula auricularia). Evolution 52:260.

491 Wong JWY, Kölliker M (2014) Effects of food restriction across stages of juvenile and early adult development on body weight, survival and adult life history. J Evol Biol 27:2420-30. doi: 10.1111/jeb.12484

494 Wong JWY, Kölliker M (2012) The effect of female condition on maternal care in the 495 European earwig. Ethology 118:450-459. doi: 10.1111/j.1439-0310.2012.02030.x 
498 standard error (SE), as well as the number of replicates in which it has been measured (N).

\begin{tabular}{|c|c|c|c|c|c|c|c|c|c|c|c|c|c|c|c|c|c|c|c|c|c|c|c|c|}
\hline & \multicolumn{8}{|c|}{ GIRONA } & \multicolumn{8}{|c|}{ MONT BLANC } & \multicolumn{8}{|c|}{ VINCENNES } \\
\hline & \multicolumn{4}{|c|}{ First clutch } & \multicolumn{4}{|c|}{ Second clutch } & \multicolumn{4}{|c|}{ First clutch } & \multicolumn{4}{|c|}{ Second clutch } & \multicolumn{4}{|c|}{ First clutch } & \multicolumn{4}{|c|}{ Second clutch } \\
\hline & Mean & \pm & SE & $N$ & Mean & \pm & SE & $N$ & Mean & \pm & SE & $N$ & Mean & \pm & SE & $N$ & Mean & \pm & SE & $N$ & Mean & \pm & SE & N \\
\hline Egg developmental time (days) & 37.58 & \pm & 2.33 & 52 & 15.10 & \pm & 0.09 & 52 & 54.97 & \pm & 1.87 & 39 & 14.64 & \pm & 0.12 & 39 & 22.82 & \pm & 0.83 & 45 & 15.38 & \pm & 0.09 & 45 \\
\hline Nymph number day 1 & 63.44 & \pm & 1.43 & 52 & 38.12 & \pm & 1.96 & 52 & 54.03 & \pm & 1.76 & 39 & 27.31 & \pm & 1.77 & 39 & 31.53 & \pm & 1.75 & 45 & 16.00 & \pm & 1.3 & 45 \\
\hline Nymph weight day 1 (mg) & 1.44 & \pm & 0.03 & 52 & 1.38 & \pm & 0.04 & 52 & 1.58 & \pm & 0.04 & 36 & 1.42 & \pm & 0.04 & 39 & 1.35 & \pm & 0.04 & 45 & 1.49 & \pm & 0.04 & 45 \\
\hline Nymph number dat 14 & 60.19 & \pm & 1.56 & 52 & 36.87 & \pm & 1.95 & 52 & 51.67 & \pm & 1.66 & 39 & 26.21 & \pm & 1.74 & 39 & 29.82 & \pm & 1.64 & 45 & 14.22 & \pm & 1.3 & 45 \\
\hline Nymph weight day 14 (mg) & 2.83 & \pm & 0.06 & 52 & 2.93 & \pm & 0.09 & 52 & 3.04 & \pm & 0.1 & 36 & 3.01 & \pm & 0.11 & 39 & 2.60 & \pm & 0.07 & 45 & 2.90 & \pm & 0.08 & 45 \\
\hline Mother weight day 1 (mg) & 58.79 & \pm & 1.21 & 52 & 59.02 & \pm & 1.38 & 52 & 51.22 & \pm & 1.49 & 36 & 53.85 & \pm & 1.46 & 38 & 44.78 & \pm & 0.96 & 45 & 44.51 & \pm & 1.01 & 45 \\
\hline Mother weight day 14 (mg) & 71.90 & \pm & 1.62 & 52 & 70.30 & \pm & 1.6 & 52 & 64.35 & \pm & 1.86 & 36 & 61.30 & \pm & 1.72 & 38 & 55.32 & \pm & 1.51 & 45 & 50.24 & \pm & 1.39 & 45 \\
\hline Brood defence & 21.42 & \pm & 2.4 & 52 & 21.12 & \pm & 2.46 & 52 & 17.97 & \pm & 2.28 & 35 & 23.13 & \pm & 3.17 & 38 & 12.11 & \pm & 1.48 & 44 & 16.98 & \pm & 2.65 & 43 \\
\hline Food provisioning & 11.22 & \pm & 1.48 & 51 & 11.00 & \pm & 1.95 & 42 & 15.59 & \pm & 2.61 & 36 & 13.35 & \pm & 2.89 & 32 & 11.38 & \pm & 2.41 & 44 & 17.54 & \pm & 3.54 & 29 \\
\hline
\end{tabular}


499 Table 2: Loadings of the five first Principal Component (PCs) reflecting single or 500 combinations of eleven life-history traits. The traits having significant loadings on each PC 501 are in bold.

\begin{tabular}{lrrrrr} 
& PC1 & PC2 & PC3 & PC4 & PC5 \\
\hline Egg developmental time & 0.591 & 0.153 & $\mathbf{0 . 5 8 4}$ & 0.005 & -0.265 \\
Egg number & $\mathbf{0 . 9 3 1}$ & 0.032 & 0.129 & -0.045 & 0.004 \\
Nymph number d1 & $\mathbf{0 . 9 3 1}$ & -0.248 & 0.156 & -0.021 & 0.021 \\
Nymph number d14 & $\mathbf{0 . 9 2 3}$ & -0.243 & 0.151 & -0.031 & 0.016 \\
Nymph weight d1 & -0.071 & $\mathbf{0 . 8 5 9}$ & 0.066 & 0.013 & -0.238 \\
Nymph weight d14 & -0.092 & $\mathbf{0 . 8 5 9}$ & 0.019 & 0.204 & -0.142 \\
Nymphs dvpt time til 2nd instars & 0.005 & $-\mathbf{0 . 7 3 7}$ & -0.269 & 0.045 & 0.076 \\
Mother weight d1 & 0.591 & 0.396 & -0.631 & -0.077 & 0.106 \\
Mother weight d14 & 0.667 & 0.439 & -0.497 & -0.086 & 0.093 \\
Food provisioning & -0.072 & 0.450 & 0.387 & -0.059 & $\mathbf{0 . 7 9 0}$ \\
Brood defence & 0.214 & -0.073 & -0.053 & $\mathbf{0 . 9 6 2}$ & 0.098 \\
\hline Variance explained (\%) & 34.5 & 24.7 & 11.6 & 9.0 & 7.3 \\
Cumulative variance explained (\%) & 34.5 & 59.2 & 70.8 & 79.8 & 87.2 \\
\hline
\end{tabular}


502 Table 3: Influence of population, juvenile's cohort and their interaction on the five principal 503 components (PC1 to PC5) based on the 11 measured life-history traits. Values obtained 504 from LMMs. Significant $p$-values are in bold.

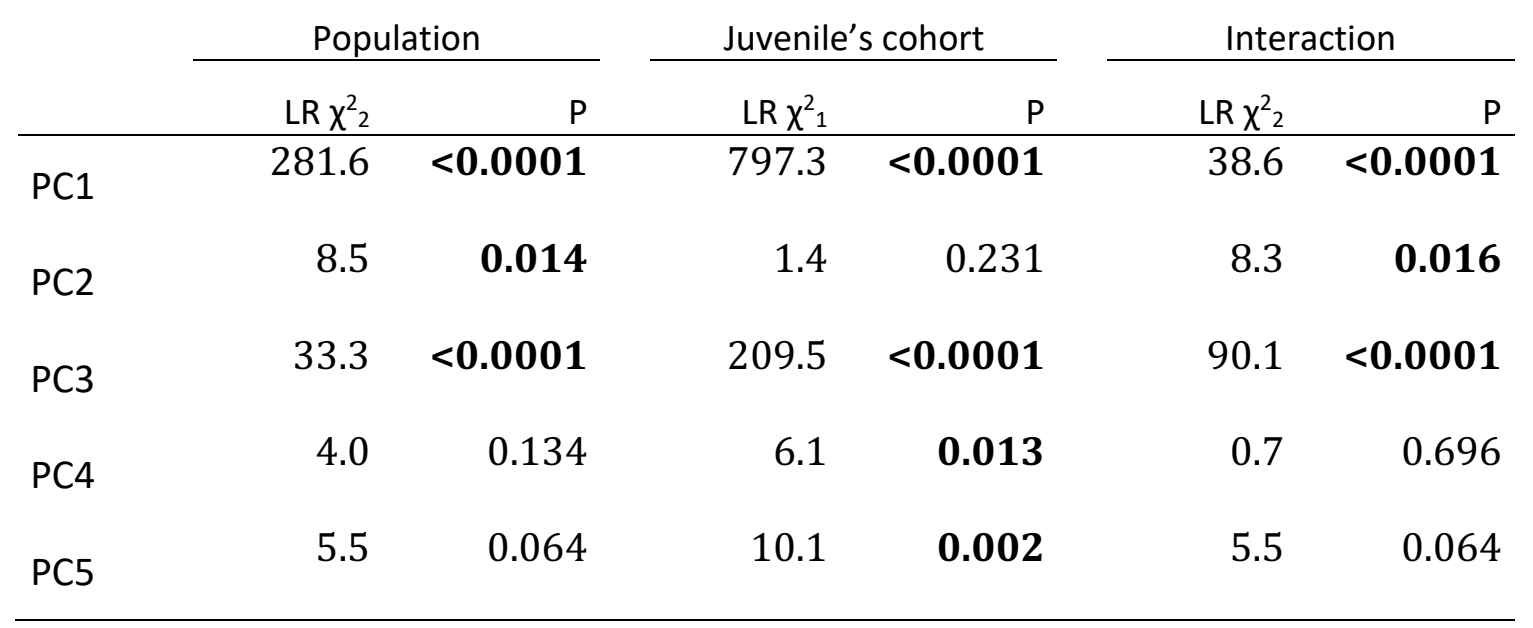


505 Table 4: Influence of first clutch values, population and their interaction on the five PCs.

506 Significant P-values are in bold.

\begin{tabular}{|c|c|c|c|c|c|c|}
\hline \multirow{2}{*}{$\begin{array}{l}2 \text { nd clutch } \\
\text { values }\end{array}$} & \multicolumn{2}{|c|}{ Population } & \multicolumn{2}{|c|}{ 1st clutch values } & \multicolumn{2}{|c|}{ Interaction } \\
\hline & $F_{(2,130)}$ & $P$ & $F_{(1,130)}$ & $P$ & $F_{(2,130)}$ & \\
\hline PC1 & 11.26 & $<0.0001$ & 81.26 & $<0.0001$ & 0.83 & 0.4395 \\
\hline PC2 & 0.36 & 0.7002 & 16.91 & $<0.0001$ & 0.11 & 0.8997 \\
\hline PC3 & 35.18 & $<0.0001$ & 40.27 & $<0.0001$ & 0.01 & 0.9859 \\
\hline PC4 & 0.54 & 0.5841 & 23.97 & $<0.0001$ & 0.56 & 0.5711 \\
\hline PC5 & 1.98 & 0.1428 & 1.00 & 0.3193 & 2.24 & 0.1102 \\
\hline
\end{tabular}




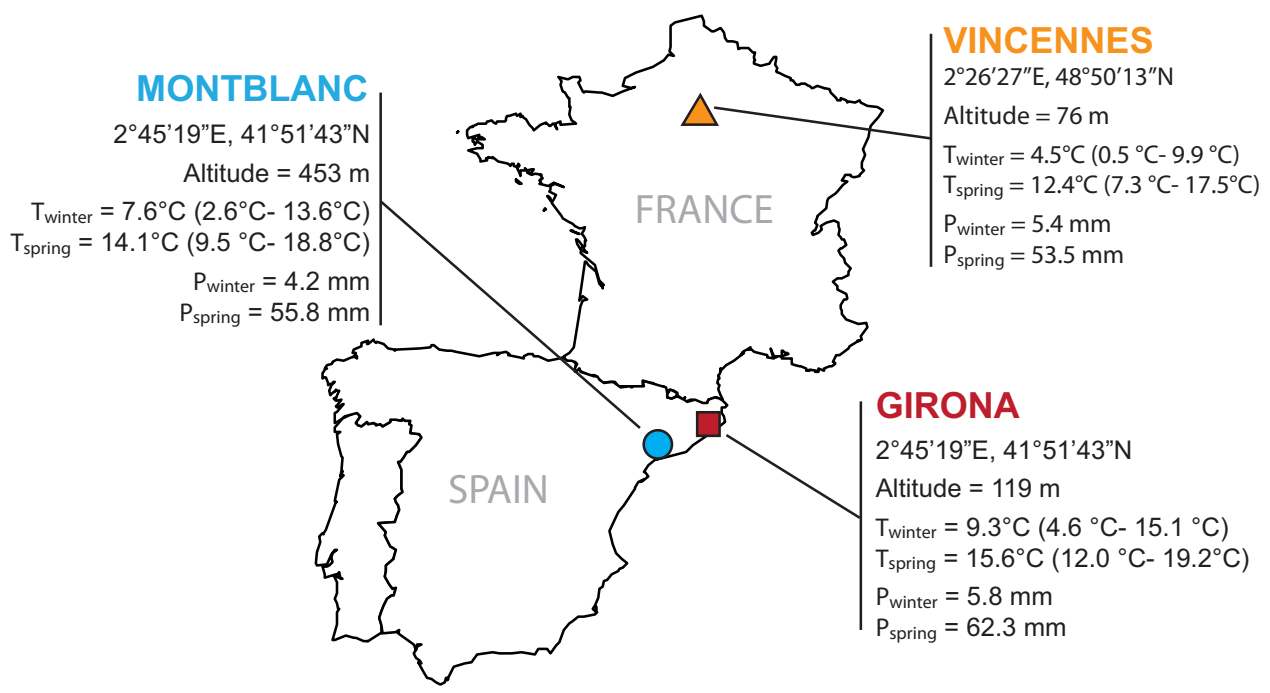

507

508 Figure 1. Location and climatic details of the three studied populations of F. auricularia. For

509 each population, we provide the GPS coordinates and altitude, as well as the mean

510 (minimum - maximum) temperatures and the mean precipitations recorded in winter and

511 spring over the last 50 years. Information from the Worldclim data base

512 (http://www.worldclim.org/).

513 

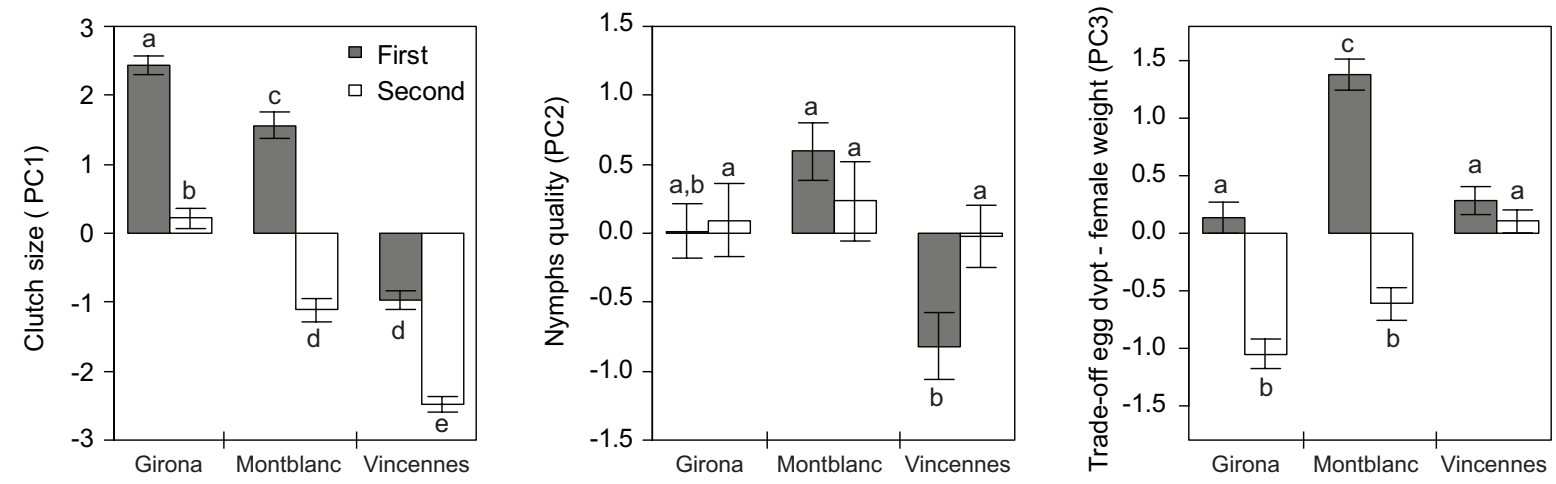

515 Figure 2. Interactive effects of population and the juveniles' cohort on the principal 516 components reflecting clutch size (PC1), nymph quality (PC2) and the trade-off between egg

517 developmental time and the mother's weight at egg hatching (PC3). Values represent 518 means \pm s.e.m. Different letters indicate significant differences (see Table S2 for detailed 519 values of pairwise comparisons). 

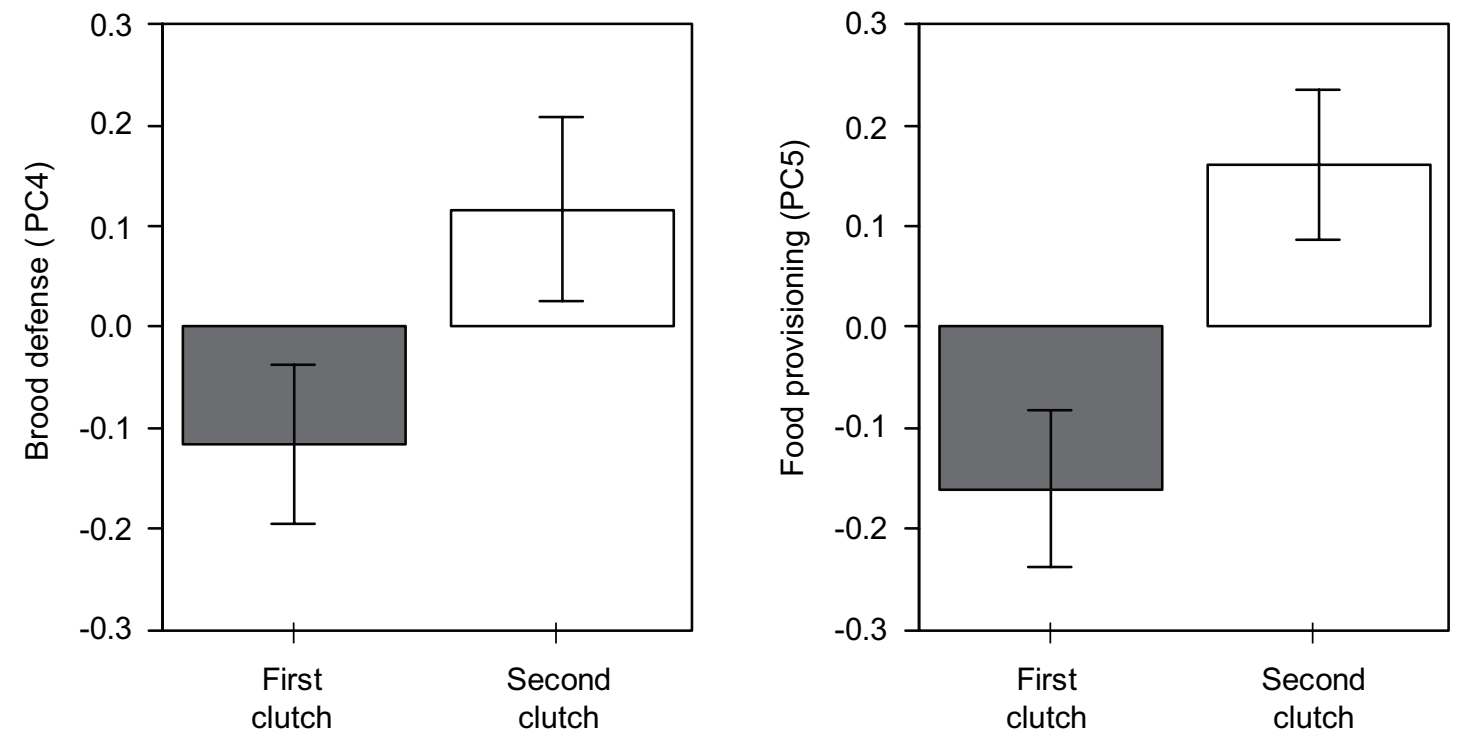

522 Figure 3. Influence of juveniles' cohort on the principal components reflecting brood

523 defence (PC4) and food provisioning (PC5). Values represent means \pm s.e.m. 

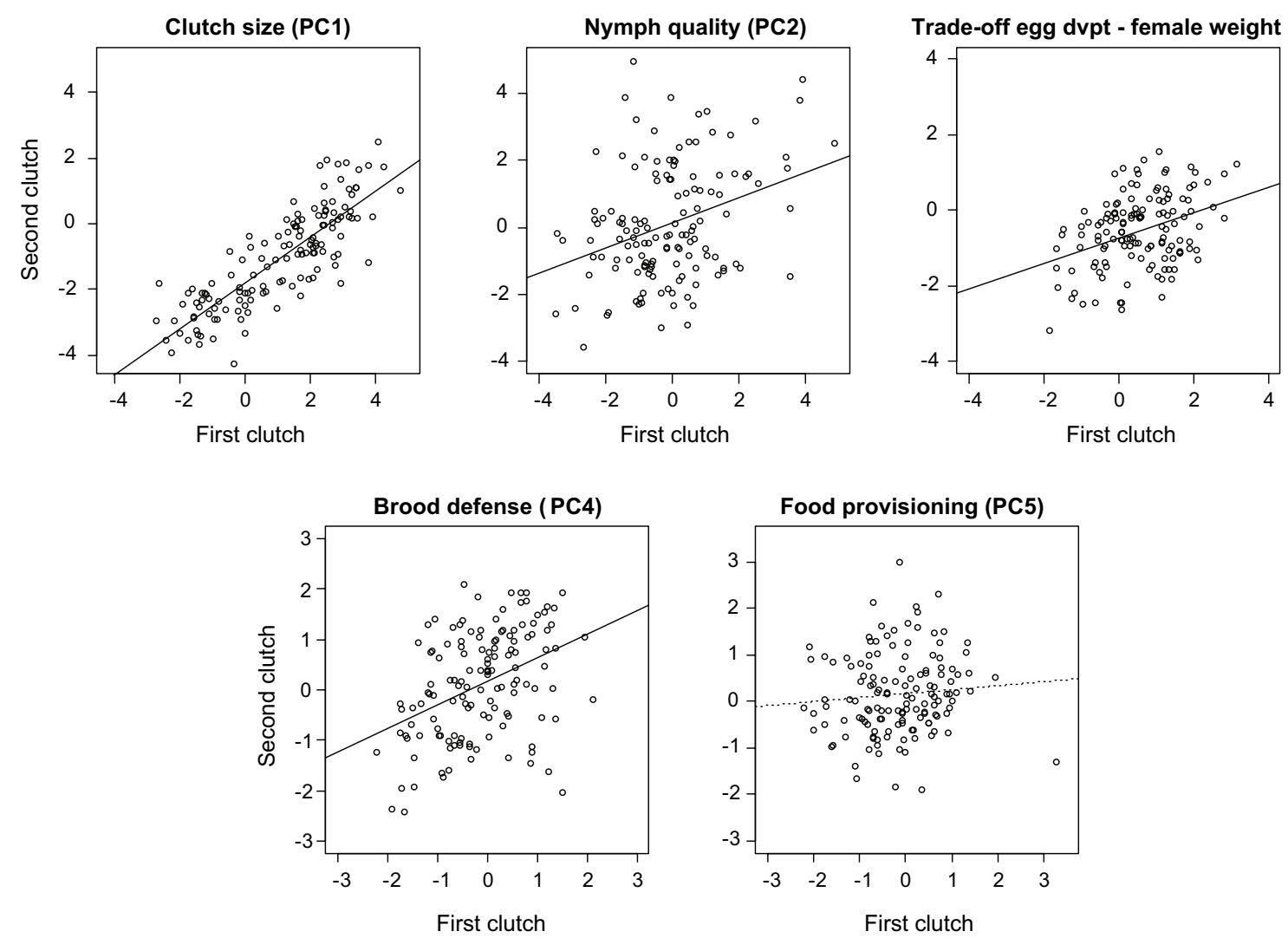

524 Figure 4. Associations between PC-values of the $1^{\text {st }}$ and $2^{\text {nd }}$ clutches. 